\title{
GESTIONANDO LA CIUdAdANíA PLURICULTURAL: \\ LA ESCUELA INDÍGENA EN CHIAPAS \\ ANTE LOS DERECHOS CULTURALES
}

\section{Management of Multicultural Citizenship: THE INDIgENOUS SCHOOL IN ChIAPAS in Face of Cultural Rights}

\section{Victoria Borrell Velasco ${ }^{1}$}

Resumen: En una relación intercultural históricamente asimétrica, las formulaciones que afectan a las oportunidades educativas de los pueblos originarios en el sistema público de educación se enfrentan a múltiples obstáculos. La enculturación en las escuelas indígenas dificulta el desarrollo de identidades múltiples homologables realmente funcionales para la construcción de una ciudadanía pluricultural, ya que se fomenta la tolerancia hacia pedagogías colonizadoras. Las tendencias que se originan a través de estos procesos educativos neocolonialistas, que atentan contra los derechos culturales reconocidos en las leyes, son conflictivas y contradictorias, tanto las que refuerzan la identidad étnica asumiendo una posición subalterna como las que la rechazan buscando vías de asimilación. En la resolución de este dilema apenas existe presencia indígena, ya que tradicionalmente, a pesar de los desarrollos normativos en el marco de los derechos culturales, los pueblos originarios quedan relegados de las consideraciones y de la toma de decisiones relacionadas con la educación.

\footnotetext{
${ }^{1}$ Doctora en antropología social. Investigadora. Universidad de Huelva, Facultad de Humanidades, Departamento de Historia II, Campus de "El Carmen". Avenida Tres de Marzo, s/n, CP 21071, Huelva, España. Correo electrónico: borrellvelasco@yahoo.es Fecha de recepción: 1101 16; Fecha de aceptación: 070416.
}

(oc) EY-No-ND Páginas 107-142. 
Este trabajo de investigación pretende evidenciar tanto las principales actuaciones del sistema educativo nacional en las escuelas de población originaria, ante el reto de los derechos culturales, como identificar las respuestas de los pueblos indígenas en relación con estos derechos en el estado de Chiapas.

Palabras clave: educación intercultural, pueblos originarios, derechos culturales.

Abstract: In an historically asymmetric intercultural relation, formulations that concern original peoples' educational opportunities in the public system face multiple obstacles. Inculturation in indigenous schools impedes the development of multiple equivalent identities that are functional for the construction of multicultural citizenship since it promotes tolerance towards colonialist pedagogies. Trends that originate from these neocolonialist educational processes, which infringe upon cultural rights acknowledged in the legal system, are troublesome and contradictory, including both those that reinforce ethnic identity from a subaltern position and those that reject it seeking routes of assimilation. Indigenous presence is scarce in this dilemma's resolution in spite of cultural rights normative developments, because traditionally original people are relegated from decision-making in education.

This piece of investigation expects to highlight the principal actions of the educational national system in indigenous schools, in face of cultural rights, as well as to identify indigenous replies to these rights in Chiapas's State.

Keywords: multicultural education, indigenous people, cultural rights. 
Dicen que hubo una vez una cultura madre que surgió en las costas de Chiapas y Guatemala hace más de cuatro mil ańos y que esa cultura madre es el ancestro de la gran

diversidad de los pueblos y culturas de Mesoamérica...

(Lomelí, 2014: 47)

Las políticas que favorecen la inclusión y la participación de todos los ciudadanos garantizan la cohesión social, la vitalidad de la sociedad civil y la paz. Definido de esta manera, el pluralismo cultural constituye la respuesta política al hecho de la diversidad cultural (Art. 2 Declaración Universal de la Unesco sobre Diversidad Cultural, 2001)

Con la científica intención de "no disparar sobre el utopista" (De Sousa, 2003: 375), me mantendré en la posición de quien pretende analizar una realidad compleja tejida por los modelos educativos en las escuelas indígenas, cuestionando su pretendida labor de atención a la diversidad étnica y cultural, dentro del marco de los derechos culturales. ${ }^{2}$

En el desarrollo de los estudios socioculturales hay momentos que resultan especialmente atractivos y oportunos, además de por la complejidad e importancia de los fenómenos, por sus circunstancias coyunturales. Éste es el caso de la educación en México que, en su versión destinada a la infancia indígena, ha sido tradicionalmente concebida como un instrumento de control y una estrategia de integración. ${ }^{3}$ Sin embargo, desde hace dos años cuenta con una ley que contempla reformas importantes adaptadas a las disposiciones de los

2 "Los derechos culturales son parte integrante de los derechos humanos y, al igual que los demás, son universales, indivisibles e interdependientes. Su promoción y respeto cabales son esenciales para mantener la dignidad humana y para la interacción social positiva de individuos y comunidades en un mundo caracterizado por la diversidad y la pluralidad cultural". Comité de derechos económicos, sociales y culturales de la ONU en su $43^{\circ}$ periodo de sesiones y en la observación general no 41.I.

${ }^{3}$ El sistema escolar chiapaneco ha sufrido en el último siglo decenas de diseños y reformas, desde la política indigenista hasta la actual educación bilingüe e intercultural, casi siempre destinados a la integración nacional y la unificación social y cultural (Silas, 2012). 
convenios internacionales que defienden los derechos de los pueblos indígenas y la diversidad cultural. Por otra parte, la infancia mexicana no ha contado con una normativa adecuada hasta muy recientemente. ${ }^{4}$ La Ley federal de Derechos de niños, niñas y adolescentes se aprobó en 2014. La normativa sobre derechos de la infancia y la ley de educación, articuladas con la referida al reconocimiento de los derechos culturales, pueden enriquecer sensiblemente las políticas tanto educativas como culturales que afectan a la población indígena. Es por lo que el presente estudio resulta oportuno en el tiempo y pertinente en el enfoque.

La educación indígena en Chiapas ha sido de gran interés para la investigación antropológica desde hace décadas. ${ }^{5}$ Sin embargo, las perspectivas más novedosas surgen a partir de 1994 cuando se pone en cuestión la posición de los pueblos originarios en el conjunto de la nación mexicana, surgiendo experiencias educativas de carácter autónomo. ${ }^{6}$ Nace entonces una corriente que interpreta la educación como estrategia de desarrollo con un papel esencial en la construcción de la autodeterminación de los pueblos y atendiendo a sus potencialidades como herramientas imprescindibles para la incorporación de los indígenas en los procesos políticos nacionales (Bertely, 2007; Lomelí, 2014).

Hasta ese momento, los enfoques tradicionales se centraban en cuestiones como las desventajas culturales o los sujetos de opresión y marginación, poniendo su atención sobre las políticas educativas, con

\footnotetext{
${ }^{4}$ La Ley federal de Derechos de niños, niñas y adolescentes se aprobó en 2014. Chiapas, en estos días, elabora sus propuestas para aproximar la normativa federal a la realidad plural de su territorio, recogiendo sugerencias de todos los actores implicados, como muestra el informe para la nueva ley de niñas, niños y adolescentes en Chiapas denominado "La infancia cuenta", presentado el 7 de abril de 2015 en San Cristóbal de Las Casas por Redim.

${ }^{5}$ Se destaca en este sentido la producción investigadora en torno a las iniciativas correspondientes a las Misiones Culturales y al Departamento de Asuntos indígenas entre 1920 y 1940 en su afán por convertir a los indígenas en mexicanos nacionales con políticas de integración forzada, y que continúa con la extensa labor investigadora del Instituto Nacional Indígenista desde la década de los 40 hasta 1975 en que la Secretaría de Educación, con la incorporación de la educación bilingüe e intercultural, ensaya numerosos proyectos y reformas que llegan a nuestros días (Silas, 2012).

${ }^{6}$ Experiencias alternativas a las prácticas educativas de carácter oficial que surgen en los municipios autónomos después de 1994 y cuyo transcurso ha sido profundamente estudiado por Bruno Baronnet (2009).
} 
el fin de delimitar su alcance o cuestionarlo, y en las prácticas educativas cotidianas, con la intención de evaluar sus logros o fracasos respecto de aquellas políticas. No es habitual encontrar análisis con un enfoque múltiple de ausencias y emergencias (De Sousa, 2010) que conduzcan a vislumbrar, por un lado, las tendencias — como consecuencias de la praxis - y, por otro, las posibilidades y espacios de acción — deteniéndose tanto en la deconstrucción de las condiciones que vertebran el presente como en los requisitos de experiencias alternativas futuras-. En esta línea es en la que pretendo inscribir mi trabajo, con el fin de identificar los hitos que obstaculizan la construcción de una ciudadanía pluricultural, co-partícipe de las ventajas y el bienestar, así como de visibilizar el conjunto de acciones positivas o buenas prácticas que dirigen su esfuerzo hacia formas de convivencia más democráticas y justas.

El derecho a la educación, de carácter civil y cultural, debe ser respetado, protegido e impulsado activamente por los Estados según pautas definidas también, y sobre todo, por los propios titulares de ese derecho. ${ }^{7} \mathrm{Y}$ es aquí donde comienzan las primeras lagunas en Chiapas, ya que la población indígena constituye $27 \%$ del total, ${ }^{8}$ siendo en la región Altos hasta de 70\%, con tendencia ascendente desde 1994. Sin embargo, su representación en la toma de decisiones es escasa y los resultados educativos señalan negativamente a este sector de población. ${ }^{?}$ Su situación se relaciona estrechamente con el porcentaje de población que vive en este territorio en condiciones muy precarias (78\%).

\footnotetext{
${ }^{7}$ Hechos como la adhesión a la Declaración de los derechos humanos, la Declaración de México de 1982, la ratificación del Convenio 169 de la OIT de 1989 (arts. 26 a 31), la adhesión a la Declaración de derechos de las minorías de 1992, a la Declaración universal sobre diversidad cultural de 2001, a la Carta de derechos de los pueblos indígenas de 2007 y el reconocimiento de México como nación pluriétnica y pluricultural, han ido construyendo la trama del actual sistema que genera múltiples formas de producir políticas culturales y educativas a favor de la diversidad.

${ }^{8}$ Aunque los datos oficiales hablan de una reducción considerable de la población indígena de $16 \%$ a 6,5\% en setenta años. Juan Carlos Silas (2012) también afirma que se subestiman sus necesidades al disminuir el número y que las cifran bailan en millones de personas.

${ }^{9}$ Los datos consultados en Inegi indican que hay 37\% de población mayor de 15 años sin educación primaria y $21 \%$ de población analfabeta (Schmelkes, 2013).
} 
El aumento de la pobreza es una tendencia que se aleja de los compromisos normativos que defienden los derechos. Nos encontramos, pues, en un contexto lleno de desventajas - muchas de las cuales tienen su origen en el desigual e histórico reparto de recursos- que se reproduce en estrecha relación con la discriminación étnica y cultural. ${ }^{10}$

En el ámbito educativo, los problemas surgen tanto por la diversidad de actores sociales implicados como por los marcos sociojurídicos actuales que organizan el sistema. Las prácticas escolares en Chiapas, diversas y hasta en ocasiones caóticas, han estado caracterizadas por pautas contradictorias de segregación/asimilación basadas en razones políticas. Desde el enfoque de la pedagogía crítica, se habla de una exclusión determinada por variables como la pobreza, la ruralidad y la pertenencia étnica. Sus consecuencias han afectado la vida cotidiana de los pueblos:

Existe dominación cuando la integridad de los valores, las prácticas y las instituciones de un pueblo no son respetadas, cuando sus conocimientos y tradiciones son discriminados y no se transmiten por la vía escolar, cuando los desarrollistas desconocen los aportes tecnológicos propiamente indígenas, cuando la jurisdicción indígena no tiene valor legal, cuando las autoridades indígenas y sus decisiones son menospreciadas e ignoradas por las autoridades estatales, afirma Gasché (Bertely, 2007: 36).

La educación juega un papel fundamental en la dinámica cambiante de relaciones socioeconómicas y políticas siendo esencial para la construcción de una ciudadanía pluricultural. Sin embargo, las normas legales aparecen como una declaración de intenciones que neutraliza los proyectos de resistencia y transformación estableciendo una brecha

${ }^{10}$ Otros datos amplían el estado de la cuestión en Chiapas: dos tercios de la infancia no escolarizada es indígena; $27 \%$ de analfabetos indígenas frente a 5,4\% no indígena; $30 \%$ de los indígenas asiste a preescolares y primarias no indígenas (Coordinación General de Educación Intercultural y Bilingüe, 2002). Aunque estudios recientes revelan en definitiva que las estadísticas referidas al mundo indígena son incompletas y discriminatorias (Schmelkes, 2013). 
importante entre la normativa y la vida. ${ }^{11}$ Arrebatar el derecho a una educación propia es arrebatar el derecho a la cultura, a la propia idiosincrasia de los pueblos e incluso a su futuro, por lo que resultan urgentes estudios multidisciplinares en este sentido.

La hipótesis que manejo es que parece improbable el surgimiento de una ciudadanía pluricultural a partir de las estrategias educativas actuales en Chiapas ya que, por el momento, la atención a la diversidad cultural en el marco legislativo presenta ciertas debilidades y no se percibe la correlación necesaria de acciones entre los actores principales de dicha pluralidad ni la implementación de recursos para que así sea. Por el contrario, los controles e injerencias, los conflictos y enfrentamientos, las dependencias y lealtades, los proyectos personales o las ventajas selectivas, en el seno de los pueblos originarios, y la inconsistencia de algunas de las políticas educativas así como la incoherencia en las prácticas sobre el terreno, crean disfunciones densas. Así las cosas, la convivencia intercultural se convierte en un anhelo dentro del marco de la utopía. ${ }^{12}$

\section{Escuelas indígenas, derechos culturales y ciudadanía pluri- cultural. Marco teórico y conceptual}

Analizar la atención a la diversidad desde las reflexiones y aportes de los derechos culturales, teniendo en cuenta las intenciones de las normativas más recientes, requiere plantear, al menos, tres conceptos fundamentales: la educación en la escuela, la ciudadanía en relación con la comunidad, y los derechos culturales tanto individuales como colectivos, dentro de la propuesta de análisis global de las ausencias y emergencias

${ }^{11}$ Si existe un hecho relevante para ilustrar esta afirmación es, sin duda, el incumplimiento de los Acuerdos de San Andrés Larráinzar. A partir de esta posición del gobierno, que reafirmó la desconfianza de la población indígena y de sus líderes, los cambios implementados a todos los niveles, incluyendo la educación, son fruto de la disfunción. Ante el incumplimiento de dichos Acuerdos de San Andrés "ninguna instancia internacional solicitó explicación alguna en torno a la lentitud, la burocratización y la insuficiencia de las medidas tomadas, con excepción de la Corte Interamericana de Derechos Humanos. Aumentó con ello la desconfianza de los pueblos indígenas en la legalidad, la democracia representativa y los sistemas de justicia" (Bertely, 2007: 21).

${ }^{12}$ Una ciudadanía intercultural bien entendida debe, por ello, "atender los aspectos que limitan las oportunidades para mejorar las condiciones de vida ... entre los que están el empobrecimiento ... y el deterioro del medio ambiente y los recursos naturales debido a una sobre-explotación que origina mayores niveles de pobreza” (Bertely, 2007: 12). 
que propone De Sousa (2010). Este autor denomina ausencias o "no existencias" a lo que yo prefiero llamar "invisibilidades" porque, estando presentes, las experiencias son ignoradas por la monocultura del saber. Una de las invisibilidades principales relacionadas con la educación aglutina las iniciativas desarrolladas en los municipios autónomos al amparo de la filosofía zapatista, tema que analicé en un estudio anterior (Borrell, 2012).

El arraigo, la pertenencia a un territorio, los vínculos, la acción colectiva, la causa común, el bienestar compartido, son características adscritas al concepto de ciudadanía (Bauman, 2004). Analizando el mundo de la vida de los pueblos indígenas de Chiapas se observan muchos de estos rasgos en redes familiares, apoyo mutuo, reciprocidad y organización asamblearia, que han permanecido en el tiempo y son reconocibles en sus interacciones cotidianas. Entonces, por qué hablar de ciudadanía como un proyecto de futuro si es una realidad presente. La clave está en observar que la ciudadanía indígena parece no existir porque ha recibido tradicionalmente el nombre de comunidad y es únicamente reconocida y reivindicada por un sector de población que presenta diversidad étnica, habla lengua indígena, vive en la pobreza o la precariedad y habita especialmente en zonas rurales.

Frente a este conjunto de población se perfila otro, vinculado con la modernidad, que trata de definir un mundo a su medida dentro de un discurso en el que sólo en teoría caben todos y que manifiesta supuestas características incluyentes. Estos ciudadanos, no indígenas, proponen un modelo de ciudadanía en un contexto de democracia representativa de carácter moderno y occidental que poco tiene que ver con las atribuciones propias de la comunidad real. Para lograrlo, desde una posición hegemónica diseñan un modelo escolar con sus propios valores, normalizado, en el que tratan de ubicar a los ciudadanos indígenas a través de prácticas denominadas bilingües e interculturales.

Se observa, pues, una asimetría que cuestiona la justicia, ya que "la tiranía se da cada vez que una fracción de ciudadanos impone sus propias ideas a los demás" (Bauman, 2004: 52), incluso cuando esta imposición toma forma en leyes pretendidamente favorables a la población excluida. Según la lógica de la clasificación social, en el ámbito de las 
ausencias, la jerarquía conlleva dominación y "puede ser incluso considerada como una obligación de quien es clasificado como superior" (De Sousa, 2010: 23). En el tema que me ocupa, la propia definición de los derechos culturales, la adhesión a su contenido y el desarrollo educativo en las escuelas indígenas oficiales son interpretados como una carga del Estado, en su misión de integrar a una población que considera "de una inferioridad insuperable" (De Sousa, 2010: 23). Para ilustrar esta idea me he detenido en la recién desplazada Ley de educación de Chiapas de 2002 que proponía "promover el establecimiento de un marco normativo que proporcione certidumbre a la sociedad en su conjunto [...] con las siguientes políticas transversales: equidad y género, pueblos indios, aprovechamiento sustentable de los recursos..." (Ley de Educación de Chiapas, 2002: 1), manifestando que es producto de la participación ciudadana. ${ }^{13}$ Sin embargo, una participación representativa que tome en cuenta los intereses y necesidades de la ciudadanía demandaría la presencia de legisladores indígenas o, en su defecto, de una figura homologable representativa del mundo indígena. Por lo que la función reguladora del poder cumple su cometido, mostrando escasa sensibilidad en el diseño de los supuestos patrones de inclusión, siendo una de las posibles y sutiles formas que adopta la "tiranía" de la que habla Bauman. Se podría afirmar, entonces, que la negociación entre los rasgos de la ciudadanía moderna y los propios de la comunidad está aún por hacerse.

En este sentido, surge el concepto de ciudadanía étnica como idea que aglutina rasgos de la identidad comunitaria tradicional; así expresan los propios ciudadanos afectados: "Definimos la ciudadanía étnica como: [...] el reclamo de mantener una identidad cultural y una organización societal diferenciada dentro de un Estado, el cual a su vez debe no sólo reconocer, sino proteger y sancionar jurídicamente tales diferencias" (Bertely, 2007: 44).

13 “... resultado de la expresión y sentir de la ciudadanía ... se recibieron 127 propuestas por escrito basadas en los siguientes ejes temáticos: ... diversidad e interculturalidad; ... atención a la diversidad; ... calidad del proceso y resultados educativos: modelo educativo pertinente ... mismas que fueron analizadas por diputados quienes en conjunto con un grupo especializado en el aspecto pedagógico y jurídico ... se dieron a la tarea de analizar cada una de las propuestas..." (Ley de Educación de Chiapas, 2002: 2 y ss). 
En consecuencia, se identifica la existencia de pluralidad en las ciudadanías. Esto me lleva a otra acepción interesante por su potencial de uso en el análisis teórico y en la aplicación práctica. No se trata sólo de principios sino que puede tratarse del "concepto marco" más próximo, fuera de la utopía, al reconocimiento mutuo del otro y a la búsqueda de mecanismos que garanticen la integralidad y universalidad de los derechos humanos. Se trata de la "ciudadanía diferenciada". Para ver la relación de esta idea con las prácticas escolares indígenas me apoyo en el análisis de Kymlicka (en López, 2001: 118), debido a que su tesis sobre la ciudadanía multicultural es mediadora a la vez que dialéctica. Este autor trata de compatibilizar los derechos diferenciados de las minorías nacionales y culturales con los principios liberales de la ciudadanía, de manera que demuestra su viabilidad en contextos como el de México, con presencia de culturas originarias dentro del Estado nacional. Aquí los grupos étnicos y culturales orientan sus reclamos "hacia el reconocimiento como sociedades distintas a través del establecimiento de mecanismos que posibiliten la autonomía y el autogobierno en territorios geográfica y culturalmente demarcados" (López, 2001: 118).

Respecto al "hecho educativo", es preciso señalar que en Chiapas es complejo por la diversidad de elementos que contiene, ya que existen procesos escolares de carácter formal u oficial que compiten con aquellos invisibilizados, de naturaleza crítica o alternativa, de carácter autónomo en los municipios autodenominados rebeldes. Podría resultar coherente la existencia de un modelo educativo representativo de cada conjunto de ciudadanías, sin embargo, la población indígena está dividida entre la escuela oficial y la autónoma, lo cual complica más el análisis porque el criterio de etnicidad no es una variable útil de clasificación. La educación vista como aporte para la transformación se reconoce como un instrumento para afrontar la pobreza y la discriminación siempre que sea definido por los propios afectados. Considerada un derecho humano, ${ }^{14}$

${ }^{14}$ Art. 26. 1 Toda persona tiene derecho a la educación. La educación debe ser gratuita, al menos en lo concerniente a la instrucción elemental y fundamental. La instrucción elemental será obligatoria. La instrucción técnica y profesional habrá de ser generalizada; el acceso a los estudios superiores será igual para todos, en función de los méritos respectivos; 2 La educación tendrá por objeto el pleno desarrollo de la personalidad 
también un derecho civil y político ${ }^{15}$ y un derecho fundamental, es establecida como condición previa para el ejercicio de todas las libertades y derechos. En el caso de los pueblos indígenas, la educación es una puerta para la participación activa dentro del Estado plurinacional, y es también la clave para la defensa y protección de su cultura. En todos los documentos revisados, el derecho a la cultura parece no poder desvincularse del derecho a la educación. Los movimientos que trabajan por el desarrollo de la ciudadanía étnica inciden en el diseño de una educación apropiada tratando de conquistar niveles similares de valoración y validez como la que manifestó y defendió la Unión de maestros por la nueva educación para México en 1995 con todo su trabajo en torno a la construcción de un currículum diferenciado, ${ }^{16}$ solución educativa eficaz ante diferentes cosmovisiones. En este sentido, Horacio Gómez (2010), al investigar sobre la educación tradicional indígena, rescata varios principios fundamentales: la reciprocidad, dar y recibir consejos, la formación de la conciencia, asunción de responsabilidades, capacitación física y mental o formación para el trabajo, y la formación de la conducta o "el enderezar del corazón". Muy poco hay de todo esto en las escuelas indígenas, salvo las iniciativas ya mencionadas de Chenalhó ${ }^{17}$ o las de los municipios autónomos.

humana y el fortalecimiento del respeto a los derechos humanos y a las libertades fundamentales; favorecerá la comprensión, la tolerancia y la amistad entre todas las naciones y todos los grupos étnicos o religiosos, y promoverá el desarrollo de las actividades de las Naciones Unidas para el mantenimiento de la paz (Declaración Universal de los Derechos Humanos 1948).

${ }^{15}$ Art.18.4 Pacto internacional de derechos civiles y políticos, 1966, y Convención americana sobre D. H., San José, 1969.

${ }^{16}$ El currículum pertinente, significativo y contextualizado, se fue desarrollando con base en una extraordinaria labor de traducción e interpretación entre diversas lenguas indígenas y el español. Es oportuno revisar aquí los resultados del informe Conflicto intercultural, educación y democracia activa en México. Ciudadanía y derechos indígenas en el movimiento pedagógico intercultural bilingüe en Los Altos, la Región Norte y la Selva Lacandona de Chiapas, México (Bertely, 2007).

17 "En el ciclo escolar 1996-1997 se comenzó a trabajar con una nueva propuesta pedagógica para la educación primaria, basada en la comunidad y en la huerta agroecológica, implementándose tanto en escuelas oficiales — principalmente del Programa de educador comunitario indígena, aunque sin reconocimiento-, como en escuelas autónomas" (Bertely, 2007: 25). 


\begin{abstract}
Es importante hacer notar que aunque en Chiapas existen treinta y nueve etnias diferentes, los libros de texto sólo se han desarrollado para cinco, ciertamente las que tienen más población, pero esto deja en desventaja a los grupos étnicos minoritarios. Esta diversidad cultural y étnica reclama proyectos pedagógicos diferenciados, para que los procesos educativos sean relevantes a los contextos sociales y culturales en que se desarrollan los sujetos (Ordaz, 2006: 8).
\end{abstract}

Ante la evidencia de que los derechos educativos son regulados y protegidos por el Estado, los expertos interesados en su desarrollo han puesto en evidencia la necesidad de que se den unas precondiciones para que no sólo puedan respetarse sino, sobre todo, impulsarse activamente y con garantías reales. En síntesis, la conjunción óptima de partida sería el respeto a las libertades civiles y políticas junto a la defensa de la ciudadanía sustentada en la disminución de las desigualdades económicas y sociales (López, 2001).

En el caso de Chiapas, serían derechos diferenciados los derechos pluriétnicos, ya que las demandas de la población indígena manifiestan su deseo de inclusión y compromiso con las instituciones y, por otro lado, los derechos de representación, que defienden el reconocimiento de la igualdad en la diferencia (ibíd.).

Por estas razones, he creído oportuno analizar el tema a la luz de los "derechos culturales". En la última década este enfoque destaca dentro de los estudios antropológicos dado que plantea una innovación radical, "considera que el primer paso para otorgar poder a los sectores excluidos es precisamente reconocerlos como titulares de derechos. No se trata de personas necesitadas de alguna cosa, sino de sujetos que tienen derechos que precisan ser garantizados por los Estados" (Ventura, 2012: 95).

En el hecho educativo se ponen en juego mecanismos de integración/ segregación, de elaboración de expectativas, de adquisición de competencias, de peculiaridades en las relaciones e interacciones, de respeto a las especificidades culturales, que sólo quedarían garantizados con el reconocimiento de los derechos sociales y culturales de los pueblos en interacción. Ahora bien, uno de los principales desafíos teóricos se 
centra en la visión heterogénea que cada uno de los grupos culturales tiene como derecho cultural propio y, en consecuencia, como legado cultural, tradicional y simbólico de "su propio grupo" (Dietz, 2013) para incorporarlo como demanda educativa. En definitiva, se precisan definir derechos que reconozcan valores comunitarios como el desarrollo sostenible, la autodeterminación o el respeto a las especificidades culturales.

Al hablar de derechos culturales me refiero tanto al reconocimiento, protección y promoción de las producciones culturales de los pueblos indígenas como a su propia identidad. Es importante precisar qué son los derechos culturales para protegerlos, quién los define y desde qué poderes. Si el derecho mismo es parte de la cultura, quiénes son los encargados de definir los límites, ${ }^{18}$ el tamiz de los derechos manifiesta un universalismo que responde a la "lógica de la escala dominante" (De Sousa, 2010: 23), entendiendo lo local como invisible en el tablero de juego del diálogo intercultural.

Concluyo este apartado dejando abierto el debate de la educación como derecho individual, que resulta un tanto contradictorio y polémico en su desarrollo debido a que impone la no injerencia del Estado en cuestiones culturales, por una parte, pero a la vez demanda la protección activa por parte de éste. En el caso del derecho cultural a una educación indígena pertinente estamos ante la dicotomía planteada por Dahrendorf "de la doble cara del conflicto social moderno, el de las provisiones sin titularidades y el de las titularidades sin provisiones" (citado en López, 2001: 112). Aunque en el caso que describo el peso recae en la segunda parte de la afirmación: siendo los ciudadanos indígenas titulares del derecho a la educación, el Estado no provee de recursos ni garantías suficientes para que así se dé e incluso limita la capacidad de aprovisionamiento autónomo que han demostrado tener a partir de algunas experiencias educativas. ${ }^{19}$

\footnotetext{
${ }^{18}$ Para ampliar, véase la Declaración de Friburgo de 2007 sobre derechos culturales, y los documentos básicos de Naciones Unidas sobre también derechos culturales de 2010. ${ }^{19}$ Como las desarrolladas en las ESRAZ: Escuela Secundaria Rebelde Autónoma Zapatista, en los municipios autónomos de San Andrés Sakamch'en de los pobres, San Juan de la Libertad, San Pedro Polhó, Santa Catarina, Magdalena de la Paz, 16 de febrero y San Juan Apóstol Cancuc, todos pertenecientes al Caracol de Oventik, que analicé en
} 


\section{Abordando la interlocución. Estrategias metodológicas}

La pregunta que mueve el esfuerzo metodológico del presente trabajo es si se está produciendo el diálogo intercultural y en qué condiciones este diálogo es favorable a la diversidad cultural de forma recíproca, equitativa y solidaria, por ser estos tres de los rasgos principales que validan la atención a dicha diversidad. Consciente de la necesidad de una mirada desde todos los implicados, ya que me refiero a acontecimientos correspondientes a más de dos décadas, y sabiendo que manejo únicamente versiones sobre los hechos, detallaré la cuestión de las fuentes.

El presente trabajo es resultado de la investigación de varios años sobre la educación escolar indígena en Los Altos de Chiapas - San Cristóbal de las Casas, Zinacantán, San Juan Chamula, y San Andrés Larráinzar, entre otros municipios- En esta ocasión exceptuaré las de carácter autónomo por la propia naturaleza del estudio, aunque las tendré como referencia de las demandas del mundo indígena. Como señalé anteriormente, la escuela autónoma se interpreta como una "invisibilidad” causada por la potencia y el predominio de lo hegemónico. Dirijo mi atención sobre el binomio visible: titulares de derechos/responsables del deber, es decir, por una parte los individuos y las comunidades beneficiarias y, por otra, los destinatarios, el Estado y todos sus órganos. Para realizarlo me he basado en tres pilares fundamentales, con cierta perspectiva histórica, que corresponden a las fuentes de obtención de datos y a las estrategias metodológicas:

a. Por una parte, es el resultado de un trabajo etnográfico enfocado a identificar los obstáculos a las alternativas antihegemónicas, dentro del hecho estudiado, de manera que resulte equitativo el protagonismo de los implicados. Comencé a hacer investigación educativa en Los Altos de Chiapas en el año 1990, mediaron luego estudios intermitentes hasta el año 2010. Por esa razón, destaco como labor fundamental la realización de entrevistas a lo largo de estos años a personas representativas de diversos grupos y colectivos: infancia; familias; promotores de educación y maestros en escuelas urbanas, rurales, indígenas y no indígenas; funcionarios de la Secretaría de Educación; y miembros de

estudios anteriores. 
numerosas organizaciones sociales y civiles, especialmente en San Cristóbal de Las Casas, implicadas tanto en la presión para la elaboración de las agendas sobre políticas educativas como activas en experiencias educativas no oficiales.

b. Considero muy oportuna, como fuente de contraste, la revisión de los principales y más actuales trabajos etnográficos sobre educación indígena. ${ }^{20}$ Aunque ciertamente se trata de diferentes aproximaciones con distintos niveles de interpretación, todas coinciden en la existencia de obstáculos de carácter político, cultural y económico para que las normativas legales tomen forma sobre el terreno real de los estudiantes en sus escuelas.

c. Otro conjunto de fuentes ha sido las leyes y su desarrollo, en el ámbito educativo y de la infancia, tanto las emanadas por los cauces legales del Estado ${ }^{21}$ como las disposiciones legítimas emitidas por los pueblos originarios en resistencia, representados en su mayor parte por los incluidos en las Declaraciones de la Selva Lacandona en materia educativa, no reconocidas por el Estado, y por el contenido del Convenio 169 de la OIT. ${ }^{22}$ Enfrentar las normas vigentes a las reclamaciones legítimas constituye una estrategia metodológica muy útil para evidenciar las ausencias y las emergencias en este ámbito.

Los datos extraídos de las fuentes referidas han sido estructurados de acuerdo con cuatro categorías analíticas. Por una parte mi interés se ha centrado en la existencia o no de "reciprocidad" a varios niveles, ya que, como se ha señalado, sin ella no existe el diálogo intercultural, precondición de la convivencia y de la construcción de una ciudadanía

${ }^{20}$ Entre las que destaco a Sylvia Schmelkes (2013), Bastiani y otros (2011), Horario Gómez (2010), María Bertely (2007), Nancy Ramírez (2007), Keny Ordaz (2006), Bruno Baronnet (2013), Héctor Muñoz (2000), y Gunter Dietz (2013), entre los que aportan distintas visiones sobre la relación entre elementos humanos y políticas educativas.

${ }^{21}$ Tanto la Ley de educación federal de 2013 como la del estado de Chiapas de 2014, así como el Plan de estudios actual, la Ley federal de niñas, niños y adolescentes de 2014, y la Ley de derechos y cultura indígena de 2004.

${ }^{22}$ Se valora el "análisis del Convenio 169 de la Organización Internacional del Trabajo (OIT), como el instrumento legal de carácter internacional más avanzado para entonces en lo relativo a las aspiraciones y los derechos de los pueblos indígenas" (Bertely, 2007: 34). 
pluricultural y diferenciada. He rastreado posibles indicadores de reciprocidad, entre los cuales destaco la presencia de contenidos específicos de todas las culturas en contacto, por tanto, la existencia de diseños curriculares con representación cultural equitativa para indígenas y para no indígenas, constituiría un reconocimiento mutuo de la importancia cultural. Otro indicador de reciprocidad es la valoración paritaria u obligatoria del dominio de cualquier lengua indígena así como lo es el español y el inglés en el acceso a los puestos de las administraciones públicas y cargos políticos. Reconocer el prestigio en el dominio de una lengua indígena tanto en el gobierno como en el mercado laboral o en las instituciones del Estado ayudaría a valorar eficazmente la cultura no hegemónica.

Otra de las categorías analíticas de mi interés es la "vulnerabilidad" (Agudo, 2008: 197), entendida como las condiciones de inseguridad y el conjunto de amenazas que sufren los destinatarios de la educación, debido a que configuran los espacios idóneos para la violación de derechos. La vulnerabilidad en la escuela tiene dos resultados importantes: el absentismo frecuente, por las escasas recompensas a corto plazo para los niños y sus familias así como por las dificultades para el acceso y la permanencia, por un lado, y el abandono escolar, ${ }^{23}$ por otro.

La atención a la diversidad no debería problematizarla sino reconocerla como un recurso enriquecedor, por tanto la vulnerabilidad de la población indígena y pobre es un indicador de desigualdad frente a la otra infancia, no indígena, no pobre, no rural. Los indicadores oficiales para evaluar los impactos de los programas son: deserción escolar, aprobación, reprobación, y eficiencia terminal.

La tercera categoría analítica, frente a la existencia devulnerabilidad, es el "empoderamiento" necesario de cara a la construcción de ciudadanías plurales equiparables. El fortalecimiento de los pueblos indígenas se ha tejido basado en siglos de resistencia ante la opresión desde una posición subalterna que viene a dignificarse a partir del año 94 a través del diseño conjunto de sus demandas y de su presentación más allá de

\footnotetext{
${ }^{23}$ Menos de $1 \%$ de los jóvenes indígenas accede a la Universidad (Silas, 2012). La educación superior se orientó, hasta 1990, a que una élite indígena defendiera la cultura dominante.
} 
lo local o regional. Sin embargo, a pesar de la repercusión internacional de las denuncias de atentados contra los derechos humanos y culturales, y a pesar de haberse alcanzado acuerdos relevantes en este sentido, en la actualidad siguen sin cumplirse en Chiapas los célebres Acuerdos de San Andrés sobre Derechos y cultura indígena desde el 16 de febrero de 1996; de esta manera las modificaciones constitucionales están aún por llegar. Indicadores importantes del empoderamiento en las escuelas son: el refuerzo de la identidad, el fomento de la iniciativa personal, la asunción de retos y la participación en trabajos cooperativos, y si se hace de forma similar entre el alumnado indígena y no indígena en las escuelas mixtas. En este sentido, los datos extraídos hablan de un fuerte conformismo e individualismo, por lo que, siguiendo a Chomsky (2007), podríamos hablar de altos niveles de "domesticación" o adoctrinamiento.

He seleccionado también como categoría de análisis la "titularidad" de derechos, marco de protección desde el que lo analizo, abordando la consiguiente polémica entre la categoría de derechos individuales y colectivos. En 1992 se aprobó la Declaración sobre los derechos de las personas pertenecientes a minorías nacionales o étnicas, religiosas y lingüísticas, con la pretensión de contribuir a la estabilidad política y social de los Estados en que viven dichas minorías. El carácter occidental y etnocéntrico del documento se pone en evidencia, no existe alusión a situaciones como la de Chiapas, donde hay un porcentaje amplio de población indígena y aun así ocupa una posición subalterna respecto al control de los puestos de decisión. Es sabido que los titulares de derechos son las personas y en el caso de los derechos culturales se han de reclamar individualmente aunque se ejerciten a posteriori colectivamente. Aquí encontramos la primera desventaja en la protección y desarrollo de derechos que, por otra parte, no son vinculantes y para Estados pobres como Chiapas resultan costosos, ya que requieren un mayor esfuerzo económico en su implementación. 


\section{¿Escuela indígena para la ciudadanía pluricultural? Contradicciones necesarias}

Teniendo en cuenta que la educación escolar permite: 1) el acceso a códigos culturales compartidos, lo cual es de gran importancia para la convivencia en un marco de respeto, 2) la apropiación de códigos culturales valorados para el acceso a otros niveles de participación activa: educación superior, mercado laboral, representación sociopolítica, y 3) potencia y enriquece los códigos culturales como bienes culturales de intercambio, es decir, prepara para ejercer el derecho a los beneficios de la cultura común, ${ }^{24}$ la escuela parecería la institución perfecta para alcanzar los objetivos de la ciudadanía pluricultural. Sin embargo, el trabajo de campo revela otra realidad.

Durante la realización de entrevistas obtuve datos sobre las carencias y los logros educativos de la infancia indígena desde cada uno de los sectores implicados así como el sentir de los problemas, los conflictos y las consecuencias de la organización de un sistema escolar no sólo precario e insuficiente para la población indígena sino también aculturador y opresor.

En el análisis de la "reciprocidad", las disfunciones aparecen en todas las esferas observadas:

a. La presencia minoritaria de representantes indígenas en la elaboración de la ley de educación así como en la de Derechos de la infancia y adolescencia refleja que no hay paridad en la representación de intereses y necesidades y que la intención de consultas previas es más un protocolo formal que una realidad. ${ }^{25}$ Las políticas educativas actuales están basadas en más control y procedimientos burocráticos (MacLaren y Huertas, 2011). Las entrevistas a los técnicos y la consulta de sus informes dejan ver que parte del fracaso de las políticas educativas lo atribuyen a la falta de interés y de responsabilidad de la

${ }^{24}$ Declaración americana de derechos y deberes del hombre, 1948: art. 13 (Harvey, 2008: 3).

${ }^{25}$ El concepto "pueblos indios" aparece en la Ley de educación como un aspecto de transversalidad a tener en cuenta sin reconocer la categoría de ciudadanía indígena con necesidades propias, derechos propios y decisiones propias para afrontar los diseños educativos. Figuran como sujetos de especial protección y no como titulares de derechos. 
infancia y de sus familias. Sin embargo, cabe preguntarse cómo demandar corresponsabilidad a familias y comunidades históricamente subyugadas para un proyecto en el que no han tomado parte, considerando que muchos de ellos tienen uno propio cuyos acuerdos fueron traicionados y olvidados. La cooperación con la educación intercultural, es decir, la actitud positiva, exige un esfuerzo enorme a la infancia indígena, y la construcción de la ciudadanía es un proyecto ajeno a sus familias. Con una historia de colonización y tutelaje, muchos de ellos están expectantes ante la realidad, su participación es pasiva, mientras que en los municipios autónomos el desengaño, la desconfianza y la desesperanza funcionaron como reactivos y provocaron la acción de la educación autónoma, aunque estos procesos de educación propios resultaron muy gravosos.

b. En cuanto a los modelos académicos, se puede señalar que los diseños curriculares son comunes a toda la infancia, por lo tanto escasamente significativos como punto de partida para el aprendizaje. Se encuentra una excepción en el reconocimiento de una educación bilingüe, pero en muchos casos está ausente de los procesos reales puesto que la educación oficial envía a maestros de una lengua a enseñar a zonas donde se habla otra distinta, y las propuestas metodológicas son inoportunas para el alumnado indígena, ya que los tiempos y espacios propios no se incluyen en un sistema cerrado poco adaptado a los ritmos de trabajo y de vida de las familias indígenas. A la pregunta de si están representados los saberes y costumbres de los pueblos originarios, la respuesta de los maestros es que lo intentan, pero señalan dificultades: "a veces hablo de las tradiciones, explicando en tsotsil y en castellano", “...los alumnos no me entienden porque es diferente dialecto y los padres quieren que hable puro español”.

Lo que encontré, explorando en el Plan de estudios de México (2011: 56-59) es la existencia de los denominados "marcos curriculares", creados con la intención de reconocer conocimientos ancestrales, deberes y cosmovisión de pueblos y comunidades, y contemplar diferentes cosmovisiones a partir de pedagogías no escritas o convencionales. El Plan habla del objetivo de legitimar las lenguas en las instituciones (Plan, 2011: 63) pero el desarrollo se mantiene como una ausencia. 
La formación de maestros indígenas es también relevante para evaluar el impacto en los cambios de la educación indígena; por el momento muestra un balance negativo ya que los avances son lentos y complejos. El currículum único estuvo vigente hasta el Plan de 2011. Según éste el uso de la lengua de origen tiene una aplicación instrumental que llega hasta primaria, como procedimiento de inclusión, y se abandona en secundaria para dar paso al aprendizaje del inglés (Plan, 2011: 46).

En la actualidad, México se encuentra implementando las líneas definidas en el Programa sectorial de educación dentro del Plan nacional de desarrollo 2013-2018, cuyo objetivo 3 habla de "Asegurar mayor cobertura, inclusión y equidad educativa entre todos los grupos de la población para la construcción de una sociedad más justa”. Y dentro de éste es destacable el punto 3.4 "Impulsar la educación intercultural en todos los niveles educativos y reforzar la educación intercultural y bilingüe para poblaciones que hablen lenguas originarias" (Plan, 2011: 56) cuyas líneas de acción tratan de corregir algunas de las prácticas más negativas de la escuela indígena.

c. Las prácticas escolares reflejan cuestiones ideológicas y se concretan en conductas que se ponen en juego en las rutinas diarias, evidencian las escasas expectativas que suelen tener los maestros hacia la infancia indígena tanto en las escuelas rurales como en las urbanas, donde la población es mayoritariamente no indígena, de forma que los valores de la población mestiza siguen considerándose de mayor prestigio y validez. En el trabajo de campo realizado en las escuelas he encontrado la transmisión de valores occidentales y contenidos propios de la modernidad capitalista, como el valor de la propiedad individual referida a la tierra frente a la propiedad comunal propia del mundo indígena, la explotación irracional de los recursos vinculada al hiperconsumo opuesta a una explotación racional y controlada, el concepto de trabajo para el progreso ante otro valor vinculado a la supervivencia, tecnologías avanzadas frente a otras más tradicionales que incluyen el respeto a la tierra.

En cuanto al rol de los maestros y su situación como agentes esenciales en el proceso de enseñanza aprendizaje destacan algunas características 
que también cuestionan la reciprocidad. Las principales quejas de los maestros están relacionadas con el escaso salario, la permanente rotación, la lejanía de sus hogares, el destino en comunidades donde éstos no hablan la lengua del lugar, el absentismo del alumnado y la falta de interés por el aprendizaje. Los maestros, en ocasiones, tienen problemas sindicales que conforman luchas de poder político y pueden llegar a utilizar su magisterio como instrumento de resistencia, no implementando los cambios dirigidos por el gobierno: "También se sabe que los maestros indígenas pueden llegar a ser intermediarios entre el Estado y las comunidades (Lomelí, 2009), que paulatinamente pueden dar mayor importancia a actividades políticas de tipo caciquil (Pineda, 1993) en detrimento de las actividades de docencia" (Bastiani, 2011: 11). En general se trata de la transmisión de una educación enfocada al desarrollo y al progreso frente al ecodesarrollo que propone respetar las peculiaridades de los pueblos y la naturaleza.

De la misma forma, observando el currículum de las escuelas no indígenas o con escasa población indígena la referencia a cuestiones de diversidad cultural y representación de las culturas mexicanas es irrelevante, lo cual nos revela la ausencia de reconocimiento hacia los pueblos originarios que comparten territorio y coexisten dentro de un espacio muy jerarquizado. "La actitud negativa hacia la propia lengua muestra la preponderancia asignada al español como lengua escolar" (Bertely, 2007: 78).

Numerosos testimonios hablan de la percepción subjetiva de la infancia en relación con la escuela como un lugar en el que no se hallan integrados : “... ya no voy a la escuela porque el maestro a veces toma y golpea ... habla puro castilla y no mucho entiendo..." o "cuando llego copio el libro, me pongo a platicar, salgo a jugar ... a veces el maestro duerme...", "lo veo difícil ... no me da ganas de estudiar y no me gustan los trabajos ... pero mi mamá me dice que tengo que llegar", "no me daba ganas de ir, pues, el maestro me daba miedo".

La oposición entre lo deseable y lo posible para las familias indígenas en ocasiones se expresa como una identidad híbrida de pertenencias múltiples según las circunstancias que las empujan a aceptar valores foráneos o mestizos para asegurar su supervivencia. Queda ilustrado 
con el testimonio de un joven estudiante: “... me siento raro hablando en tseltal porque mi papá siempre me prohíbe hablar en dialecto, él dice que sólo el español me va a servir". Por un lado, aparece el deseo de libertad para la autodeterminación que se expresa a través de la demanda de una educación propia que fomente y reproduzca los valores tradicionales, por otro surge la necesidad, a corto plazo, de realizar las elecciones más acertadas para mejorar su vida, "somos pobres y no sabemos mirar bien los libros, yo quiero que mis hijos abran los ojos y hablen castilla", afirmaba con rotundidad un padre tsotsil, dentro de las escasas opciones en las condiciones de vida impuestas y/o construidas. La educación tiene para ellos gran valor y estiman positivamente el bilingüismo siempre que no retrase el aprendizaje del español como lengua de prestigio. En este sentido, muchas familias optan por elegir la vía de acceso a un mundo ajeno pero muy valorado como instrumento de transformación para el futuro de sus hijos. Las familias ofrecen cierta resistencia ante la opción intercultural por varias razones: las dificultades de escolarización y permanencia, en algunos casos, la desconfianza hacia la utilidad de los proyectos escolares y la percepción utilitarista de la escuela. Tengamos presente que muchas unidades familiares reciben apoyos económicos a cambio de la asistencia de sus hijos a la escuela, según los programas actuales de desarrollo. ${ }^{26} \mathrm{Me}$ pregunto cómo demandar corresponsabilidad a familias y comunidades históricamente subyugadas en un proyecto en el que no han tomado parte. Se ha creado una brecha interétnica importante.

Siendo la educación un asunto político, la tensión en el nivel local es permanente porque los proyectos de resistencia influyen en las expectativas y en las demandas pero casi siempre en espacios ajenos a la escuela. Las amenazas, prohibiciones y agresiones en el entorno escolar muchas veces vienen determinadas por los conflictos religiosos o por la filiación política. En los centros escolares el impacto de las pedagogías coloniales y autoritarias no permite proyectos de autodeterminación y el derecho a la cultura es arrebatado.

${ }^{26}$ De las formas de abordar el rezago escolar, el abandono y el bajo rendimiento en un sistema integrador se encuentran los programas Progresa (1997) y Oportunidades (2001), que asignan una ayuda económica a las familias por la permanencia de los escolares en las aulas. 
En lo que concierne a la "vulnerabilidad", los indicadores son muchos. En educación escolar especialmente viene dada por hechos como: nińos no registrados al nacer que no tienen derecho a la escolarización; pobreza y precariedad de sus entornos: ${ }^{27}$ trabajo infantil; migraciones estacionales; lejanía de las escuelas; falta de seguridad en los desplazamientos; descontextualización de contenidos y procedimientos trabajados en las escuelas; ${ }^{28}$ aumento del control y la violencia in trafamiliar hacia una infancia que tiene la responsabilidad de asistir, a cambio del subsidio, y rendir en una escuela no pertinente. Este aspecto, de especial relevancia, responde a la lógica de la tutela y del diseño preconcebido de las soluciones educativas para la población indígena sin contar con su proyecto propio: "No le gusta ir a la escuela, dice que el maestro maltrata pero si no llega yo también le voy a golpear...", "si no va a la escuela su papá también le da golpizas por menso, pero yo le digo que no le golpee en la cabeza, pues, digo yo que así se vuelve más menso". La cuota permitida de ausencias injustificadas está fijada en $15 \%$ al mes. Esta cantidad es causa de retirada del subsidio (Agudo, 2008). En este sentido, existen datos sobre violencia hacia la infancia obtenidos por la Red por los Derechos de la Infancia en México (Redim). ${ }^{29}$

Se mantiene la lógica de la integración y la del asistencialismo basándose en estrategias compensadoras para homogeneizar, sin poder controlar las consecuencias. Por tanto, reconocer al otro de forma recíproca parece ser la clave del cambio de paradigma, y eso en Chiapas está aún por hacer. Se observa que los retos teóricos se reelaboran y los discursos legales mejoran, sobre una trama de utopías, mientras la situación sobre el terrero no ha cambiado mucho: mayor número de escolarizados

27 "En las pruebas de aprovechamiento escolar aplicadas a niñas y niños de sexto año de primaria, la diferencia de los puntajes promedio entre primarias privadas y las indígenas suele ser considerablemente alta. Factores como el grado de hacinamiento, la disponibilidad de libros, el nivel educativo de la madre, la infraestructura educativa, entre otros, influyen en los rendimientos educativos de la población infantil indígena” (Redim, 2015).

${ }^{28}$ Los problemas sociolingüísticos derivados de la actividad docente, sin metodología y estrategias de comunicación de la lectoescritura en dos idiomas, conlleva serios problemas en el autoconcepto de los niños (Bastiani y otros, 2011).

${ }^{29}$ En http://www.derechosinfancia.org. $\mathrm{mx} /$ index.php [fecha de consulta: 5 de mayo de 2015]. 
no significa mejor escolarizados, más aulas o más maestros tampoco mejoran los rendimientos escolares. El problema fundamental está en las desigualdades económicas y en la marginación política.

Los resultados relacionados con el "empoderamiento" hablan de un trabajo lento y minucioso por parte de los líderes de organizaciones indígenas y de organizaciones sociales. Para ilustrarlo voy a contrastar dos testimonios:

Ahora son nuestros propios compañeros que vienen a trabajar porque aprendieron los libros, porque nos pusieron en sus corazones. Así deben hacer, compañeros; manden a la escuela a sus hijos para que abran sus ojos, miren bien las letras de castellano. Nosotros somos muy pobres porque no sabemos ver las letras de los libros ... No entendemos castilla, parece que están tapados nuestros ojos, nuestras bocas, y aquí en la escuela se nos van a abrir... (Pérez, 2003: 51).

Esta afirmación implica asumir un estatus subalterno de sometimiento hacia los saberes mestizos como precio de la movilidad económica y social. El segundo manifiesta:

Las niñas y los niños indígenas heredan de sus padres, de sus abuelos y de su entorno, una enorme variedad de saberes y sensibilidades que se expresan en conocimiento y relación con la naturaleza, en historias, mitos y leyendas, en música, canto y danza, en hábitos de cocina y en objetos de arte, en sus ropas y en sus rostros. Son el rostro pluriétnico y pluricultural de México (Redim, 2015).

Median entre ambos más de cinco décadas en las que no ha existido correlación entre asistencia a la escuela y superación de la pobreza, idea que mantenía la esperanza de muchas familias indígenas. Sin embargo, el esfuerzo de las organizaciones sociales fue destacable. Su labor pedagógica casi artesanal ha sido considerada por varios autores: 
... el trabajo de más de una década que han realizado organizaciones civiles e independientes como Semillitas del Sol y la Unión de Maestros de la Nueva Educación para México (Unem), las cuales han logrado desarrollar métodos pedagógicos para diversas comunidades indígenas de Chiapas (Gutiérrez, 2006; Bertely, 2007; Gómez, 2008; Baronnet, 2009) (en Bastiani y otros, 2011: 15).

Otras experiencias, del pasado reciente, reflejan el esfuerzo que supuso dentro del "mundo invisible" de las ausencias hacer aportaciones y obtener reconocimiento:

La formación de educadores indígenas en educación intercultural con diversas experiencias de aprendizaje ha dado algunos resultados como el proyecto "Tarjetas de Autoaprendizaje" de Jorge Gasché: "solamente esta unión ha logrado desarrollar un modelo pedagógico culturalmente pertinente que integra los conocimientos y la cultura indígena al trabajo escolar, algo que no ha sido posible aún en las escuelas autónomas y menos aún en las oficiales (Bertely, 2007: 29).

Muchas organizaciones han entendido que la defensa de la identidad y de los derechos culturales es el camino de la interlocución recíproca para la configuración de una nación pluricultural. Las pedagogías descoloniales se hacen presentes en escasas experiencias pero se ha iniciado el camino de la visibilidad con instrumentos propios. "Es importante ver cómo los pueblos indígenas promueven el igualitarismo y el control del ejercicio del poder egoísta y de la dominación en su seno, para construir las bases de un proyecto político liberador, democrático y solidario que involucrará a los indígenas y no indígenas" (Bertely, 2007: 34).

El trabajo de fortalecimiento toma forma en escasas pero genuinas experiencias de gran potencial motivador. En lo que atañe a la escuela se autoriza un currículum más cercano a la vida, costumbres y lengua, pero no con contenidos realmente útiles, válidos para sus intereses vitales estratégicos, de transformación de condiciones de vida como 
pueblos en proceso de emancipación. La historia reciente ha visto la transición del currículum único a incipientes propuestas de currículum diferenciado, sin embargo hay voces que defienden uno intercultural, con contenidos que representen a todos los grupos culturales, que desarrolle una identidad compartida ${ }^{30}$ para una escuela intercultural. En las visitas a las escuelas pude ver libros traducidos a tsotsil y a tseltal que no se utilizaban. Una subvención o subsidio decidido unidireccionalmente no es lo mismo que un presupuesto participativo. De la misma forma una concesión de contenidos como el currículum inclusivo o metodológica como el bilingüismo sustractivo ${ }^{31}$ no es lo mismo que un diseño educativo participativo de contenidos, competencias, metodologías y materiales. Tomaré como ejemplo el sistema de becas. Este procedimiento consigue que algunos alumnos se adapten al sistema escolar y alcancen los objetivos de la aculturación vendiéndose como modelos de éxito, como historias de salvación y renacimiento. ${ }^{32}$ La falta de equidad en la titularidad de derechos en la Constitución mexicana y otras legislaciones posteriores es un importante indicador de que la ciudadanía pluricultural aún es una utopía en Chiapas. ${ }^{33}$

Este trabajo cuestiona la gestión de la ciudadanía pluricultural en el ámbito de la educación, y las razones son varias:

\footnotetext{
${ }^{30}$ La idea de identidad compartida es desarrollada por Kymlicka, aunque no hace ninguna referencia al ámbito de la educación (en López, 2001).

${ }^{31}$ Se confirma un bilingüismo sustractivo: "la lengua se enseña para que pueda desaparecer" (De la Peña, 2002: 50).

32 Por ejemplo: http://www.eluniversal.com.mx/estados/81907.html: “Amadeo Hernández Silvano, un joven de la etnia tzeltal, originario del municipio selvático de Ocosingo fue ganador de la fase estatal del Concurso Nacional de oratoria y Debate Público 2011"; http://www.eluniversal.com.mx/nacion/189183.html: "Juan Ricardo Hopkins ganador del concurso de oratoria quiere ser político": "La política me ha gustado y me veo en la política"; http://www.proceso.com.mx/?p=394174: "Indígena chiapaneco se titula con honores como físico en la UNAM".

33 Se sugiere la lectura de la VI Declaración de la Selva Lacandona de junio de 2005 en la que se hace claramente una revisión histórica de las etapas y avances en las propuestas y acuerdos entre el EZLN y el gobierno mexicano así como las cuestiones aún pendientes. En http://enlacezapatista.ezln.org.mx/2005/11/13/sexta-declaracion-dela-selva-lacandona.
} 
- No se produce la existencia de identidades culturales homologables a nivel de estatus, prestigio o poder, para la protección y promoción de los derechos culturales de todos los grupos que coexisten en el estado.

- No funcionan las mismas reglas del juego, es decir, el acceso equitativo a la toma de decisiones para todos los grupos y el trabajo educativo no presentan logros relevantes que tiendan a la equidad, hasta el momento.

- Se ha creado una monocultura de naturalización de las diferencias. Nada se contempla de los pueblos originarios que no sea en relación con la hegemonía de la cultura mestiza. Las presiones internacionales y el reconocimiento constitucional de nación pluricultural obligan a Chiapas a intervenir activamente como garante y promotora de los derechos culturales. Sin embargo, la interculturalidad no se está negociando entre iguales, por tanto, no es posible dentro de una relación asimétrica.

Desde 1994, la organización del mundo indígena y las movilizaciones evidencian una toma de conciencia activa extraordinaria que expresa una lucha por el reconocimiento ante la negación, la injusticia, el desprecio y la humillación. La auto organización de quienes confían en el poder de la educación comenzó un camino complejo de recuperación de identidad: "nuestro proyecto: construir las bases de un modelo pedagógico liberador, democrático y reformador, encarnado en una democracia activa y solidaria que sirva de ejemplo a la sociedad no indígena" (Bertely, 2007: 66), mientras el gobierno trataba de reconocer las nuevas demandas mediante la promulgación de una nueva ley de educación:

Artículo 65.- La educación indígena tendrá las características y finalidades siguientes: I. Atender a la diversidad cultural y lingüística; II. Promover la convivencia intercultural en el respeto y derecho a la diversidad; ... XIII. Integrar en los planes y programas de estudio los conocimientos y saberes comunitarios como contenidos educativos, para impulsar el desarrollo y respeto de los valores socioculturales de los pueblos indígenas... 
No obstante, los desencuentros han sido muchos y las negociaciones poco fructíferas. El proyecto educativo mexicano es de modernidad basado en pruebas de evaluación aplicadas de forma homogénea y en español. Con las bases ya mutiladas, se trata de proyectos que se basan en consignas, en la incorporación a un mundo global que disuelve la diversidad. El mayor esfuerzo es el burocrático, como si se disputara un premio global, políticamente correcto y éticamente insuficiente.

La interpretación de los datos a la luz de los derechos y criterios establecidos por la ONU, como parte integrante de los derechos humanos en 2009, y teniendo en cuenta las consideraciones de la Declaración universal sobre la diversidad cultural, en cuyo art. 5 afirma que "toda persona tiene derecho a una educación y una formación de calidad que respeten plenamente su identidad cultural”, me lleva a los siguientes resultados:

- Las oportunidades efectivas de "accesibilidad" para la infancia indígena en el sistema educativo son muy diferentes que las existentes para la población mestiza. Se suma la pobreza a la pertenencia étnica. Las posibilidades de permanencia son mucho menores, la utilidad de las titulaciones básicas muy relativa —escasa aplicabilidad-. El racismo interfiere en el mundo laboral y en la vida cultural.

- En cuanto a la "aceptabilidad" por parte de los destinatarios, se puede señalar que la educación es aculturadora y colonialista, ya que en muchas ocasiones, cuando la permanencia lo permite, al aumentar los conocimientos y las competencias, los niños desean pertenecer al mundo mestizo en lugar de tomar conciencia y dignificar su cultura reivindicando mejoras reales. El reforzamiento de su identidad de forma libre no es una opción real en un marco de desigualdad.

- La "idoneidad" puede también ser cuestionada en el sistema educativo porque sólo tiene en cuenta los valores culturales de una minoría: $30 \%$ de la infancia indígena acude a escuelas no indígenas donde no se están implementando los marcos a los que hace referencia la ley. Si la ciudadanía indígena, según sus autoridades legítimas, ha definido los valores y rasgos comunitarios, ${ }^{34}$ ¿cuál es la razón por la

34 "De acuerdo con las autoridades educativas entrevistadas, los valores y tradiciones 
que estos contenidos aún no aparecen en los diseños curriculares?, ¿no se consideran aportes válidos para la ciudadanía pluricultural? Los resultados de la investigación reflejan para la educación escolar indígena, no autónoma, la existencia de un modelo no pertinente y no participativo, por tanto, al servicio de la reproducción de unas relaciones asimétricas.

\section{Consideraciones finales}

La meta de esta investigación era detectar tanto los obstáculos como las fortalezas en el interior de la escuela indígena para la construcción de una ciudadanía pluricultural con la mirada interpretativa puesta en los derechos culturales. Después de revisar valiosos trabajos etnográficos sobre la escuela indígena y contrastarlos con mi experiencia en el trabajo de campo, he logrado apuntar algunas cuestiones relevantes sobre el binomio ausencias/emergencias en la atención a la diversidad.

He defendido la existencia de una aguda colonización de las mentes de la infancia indígena que tiene como resultado natural la tolerancia a las injerencias aculturadoras. Me apoyo en Grosfoguel (MacLaren, 2011: 227) cuando describe el poder colonial como entramado de jerarquías y de formas de dominación encubridoras, y lo aplico al proceso por el que se arrebatan los valores indígenas tradicionales de la familia tales como el apoyo mutuo, la relación con la tierra o el concepto de dignidad, para evidenciar la existencia de una democracia desvirtuada que no cumple con la propuesta básica de Dewey como "un modo de vida asociada, compartida" (ídem: 226). La escuela para la población indígena es un ente dirigista, autoritario y no deliberativo. La infancia indígena aparece como público cautivo receptor de una educación inadecuada, donde se privilegian los valores de la cultura nacional. Una educación que produce bajo rendimiento académico

más representativos de los pueblos indígenas en Chiapas son fundamentalmente la lengua, la cultura, la religión, festividades patronales, la naturaleza — deidades como el sol, la luna, la tierra_-, ritos a la tierra para la fertilidad, mitos y leyendas, la solidaridad, la unión, la ayuda mutua, el respeto a sus mayores, el carnaval chamula, sus atuendos cotidianos y de gala, accesorios — sombreros con listones_-, el bastón de mando, catolicismo prehispánico, no propiedad a los ladinos, organización social y política, su producción artesanal —tejidos de lana” (Ordaz, 2006: 15). 
y el desarrollo de una "identidad evasiva". Los efectos incontrolados de esta desvinculación étnica son el desarrollo de proyectos de vida basados en la esperanza migratoria hacia centros de poder económico y de bienestar o la falta de planes y asunción resignada de una vida tutelada y enmarcada en la pobreza.

Una identidad que se quiere camuflar es una importante barrera para la construcción de ciudadanía pluricultural. La vulnerabilidad transformada en manipulación de la infancia indígena en la escuela bien puede resumirse en dos ideas: la escuela es el lugar donde se construye la identidad mestiza (Ramírez, 2007); y "son lugares para capataces, mayordomos y caporales" (Dietz y Mateos, 2013). Se puede afirmar que la escuela impulsa la emigración, el éxodo rural y la deconstrucción de la identidad. A su vez, la existencia de identidades múltiples que funcionan según el contexto disminuye la posibilidad de un activismo beligerante entre la población indígena. "El punto de partida de la educación en derechos para pueblos indígenas es el fortalecimiento de la propia identidad, es decir, de la identidad personal, familiar y comunitaria, pues es sobre ella que se construye la identidad ciudadana y no al revés" (Bertely, 2007: 13). En la construcción de identidad juegan un papel imprescindible la familia y los maestros. Hemos visto que ambos obstaculizan la educación intercultural tendiente a la ciudadanía pluricultural.

Un factor importante que impide la sinergia en las iniciativas tiene que ver con el desperdicio de saberes. La posición hegemónica de la educación nacional prescinde de las propuestas de los pueblos indígenas, su propio proyecto para toda la ciudadanía es algo con lo que no se cuenta para negociar y constituye otra barrera, esta vez, de procedimiento. A priori, los intereses de todos los grupos culturales son compatibles con una educación para la ciudadanía, y sería conveniente redefinir las condiciones del diálogo para establecer acuerdos interculturales.

A otro nivel, queda probado que la reciprocidad basada en el reconocimiento del otro como interlocutor en un marco de equidad, precondición para una convivencia basada en la justicia social, es una cuestión pendiente. Faltan los propios diseños autónomos como interlocutores válidos para un verdadero diálogo equitativo y paritario. En 
consecuencia, ¿qué posibilidades hay de un diálogo intercultural? Se detecta la existencia de un círculo vicioso: ¿Es posible en un contexto jerarquizado y racista como el de Chiapas, en el que cuesta reconocer efectivamente los derechos de los pueblos indígenas como conciudadanos, esperar la autoafirmación de la propia identidad y diseñar reivindicaciones en el marco de los derechos culturales?

En la Constitución de México, los derechos culturales son reconocidos tomando como referencia componentes de identidad de las comunidades indígenas — cultura, patrimonio, costumbres, lenguas, expresiones artísticas y de la religiosidad...-. Una identidad vinculada a la pobreza y a consecuencias psicosociales, como la baja autoestima, se niega oportunidades y la capacidad de tomar decisiones.

Vemos a un Estado que, en su afán por responder a las demandas activas del cumplimiento de los derechos educativos, interpreta la educación indígena como un servicio que ha de prestar a una población destinataria de las políticas públicas, como mecanismos compensadores y bienintencionados —esfuerzo por la educación bilingüe e intercultural, formación profesional, grado de maestros en lenguas indígenas...- , prescindiendo del discurso esencial de los derechos culturales como derechos generados de forma participativa. Se da la apropiación del discurso emancipador de los indígenas y su constreñimiento en los discursos legales. De la dominación se ha pasado a la regulación controlada, prescindiendo de las ideas que nutren la emancipación, la autodeterminación y la autonomía.

De las emergencias en forma de experiencias pioneras, alternativas, genuinas, se deduce que la clave para una relación intercultural paritaria es la construcción de una ciudadanía diferenciada, y el instrumento de esta génesis es una educación de acuerdo con este proyecto. El camino más idóneo es el pacto, el acuerdo entre los implicados, por encima de las recomendaciones de la ONU que sugiere preservar las condiciones en que se han creado los bienes y prácticas indígenas. Esto significaría preservar la exclusión y la pobreza y contendría una importante amenaza a la dignidad de las personas indígenas. Falta un claro proceso de negociación cultural en el que se expresen las necesidades y se respete el derecho a decidir sobre sus soluciones, en los términos 
del "buen vivir" demandado por los protagonistas durante décadas. Y, aunque se han definido las condiciones que pueden concretar la posibilidad y la innovación, los resultados parciales hablan de desencuentros potentes en la posible conversación entre ciudadanías equiparables.

\section{Bibliografía citada}

Agudo, A., 2008, "La vida social de las políticas sociales: relaciones de la producción del 'impacto' del Programa de Desarrollo Humano Oportunidades", en Sanchíz, P. y Gil Tébar (coordinadores), Marginación y pobreza en América Latina. Estrategias de supervivencia, politicas gubernamentales y acción social, Signatura Demos, Sevilla.

Baronnet, B., 2009, “Autonomía y educación indígena: Las escuelas zapatistas de las cañadas de la selva lacandona de Chiapas", México, en http://www.cedoz.org/site/pdf/cedoz_886.pdf

Baronnet, B., 2013, "Lenguas y participación comunitaria en la educación indígena en México", en AIBR Revista de Antropología Iberoamericana, vol. 8, núm. 2, mayo-agosto, pp. 183-208, Asociación de Antropólogos Iberoamericanos en Red Madrid.

Bastiani, J. Ruíz-Montoya, L. Estrada, E. Cruz, T. y Aparicio, J., 2011, "Política educativa indígena. Práctica docente, castellanización, burocracia y centralización de la educación como limitaciones del éxito pedagógico en la región Ch'ol, Chiapas”, en Revista Perfiles Educativos, vol. XXXIV, núm. 135, IISUE/UNAM, pp. 8-25.

Bauman, Z., 2004, Modernidad líquida, Fondo de Cultura Económica, Buenos Aires.

Bertely, M., 2007, Conflicto intercultural, educación y democracia activa en México. Ciudadania y derechos indígenas en el movimiento pedagógico intercultural bilingüe en Los Altos, la Región Norte y la Selva Lacandona de Chiapas, CIESAS-Papeles de la Casa Chata/ Fondo Editorial de la Pontifica Universidad Católica del Perú, México. 
Borrell, V., 2012, "La educación popular como instrumento de desarrollo endógeno en Chiapas: modelos pedagógicos alternativos", en García, C., P. Gil, y P. Sanchiz (coordinadores), Las políticas de desarrollo y cooperación de las ONG en América Latina, Universidad de Sevilla, Sevilla.

Chomsky, N., 2007, La (des)educación, Crítica, Barcelona.

Comité de Derechos Económicos, Sociales y Culturales de la ONU, en http://research.un.org/es/docs/ga/quick/regular/43

Coordinación General de Educación Intercultural y Bilingüe, 2002, en http://www.nacionmulticultural.unam.mx/100preguntas/ pregunta.php?c_pre $=65 \&$ tema $=13$

Declaración de Friburgo de 2007 sobre derechos culturales, y los documentos básicos de Naciones Unidas sobre derechos culturales de 2010.

Declaración Universal de Derechos Humanos 1948.

Declaración Universal de la Unesco sobre diversidad cultural 2001.

De la Peña, G., 2002, "La educación indígena. Consideraciones críticas”, Revista Sinéctica, núm. 20, en http://sinectica.iteso.mx/ assets/files/articulos/20_la_educacion_indigena_consideraciones_criticas.pdf

De Sousa, B., 2003, Crítica de la razón indolente. Contra el desperdicio de la experiencia, Editorial Desclée, Bilbao.

De Sousa, B., 2010, Descolonizar el saber. Reinventar el poder, Ed. Trilce, Montevideo.

Dietz, G. y L. Mateos, 2013, Interculturalidad y Educación Intercultural en México. Un análisis de los discursos nacionales e internacionales en su impacto en los modelos educativos mexicanos, Secretaría de Educación Pública, México.

Enlace Zapatista, en http://enlacezapatista.ezln.org.mx/2005/11/13/ sexta-declaracion-de-la-selva-lacandona

Gómez, H., 2010, "Educación indígena y ¿derechos humanos? En la región Altos de Chiapas. Continuación de la negación de la diversidad", en Revista de Derechos Humanos y Estudios Sociales, año 2, núm. 3, enero-junio, Facultad de Derecho de la Universidad 
Autónoma de San Luis Potosí/Departamento de Filosofía del Derecho de la Universidad de Sevilla/Departamento de Derecho de la Universidad Autónoma de Aguascalientes/Comisión Estatal de Derechos Humanos de Aguascalientes, México.

Harvey, E., 2008, Instrumentos normativos internacionales y politicas culturales nacionales, Consejo Económico y Social, Naciones Unidas, Ginebra.

Inegi, en http://www.inegi.org.mx

Ley de Educación de Chiapas 2002.

Lomelí, A., 2014, Syu'el tunneletik y mandar obedeciendo. Poder y cultural en pueblos indios de los Altos de Chiapas, Centro de Estudios Superiores de México y Centroamérica, San Cristóbal de Las Casas, Chiapas.

López, L., 2001, "Derechos económicos y sociales, derechos diferenciados y ciudadanía”, en De Sousa , B. y otros, Ciudadanía y Derechos Humanos Sociales, Escuela Nacional Sindical, Medellín. McLaren, P. y Huertas, L., 2011, “Educación pública y formación de profesores: una visión desde la pedagogía crítica revolucionaria”, en Revista Innovación Educativa, vol. 11, núm. 57, octubre-diciembre.

Muñoz, H., 2000, "Visión de la educación bilingüe en regiones indígenas de México", en http://www.lie.upn.mx/docs/Diplomados/ LineaInter/Bloque2/Enfoques/Lec9.pdf

Ordaz, K., 2006, "Educación Indígena: Un enfoque organizacional y un acercamiento a su cosmovisión", en http:// www.eumed.net

Pacto internacional de derechos civiles y políticos 1966 y Convención Americana sobre D.H. San José 1969.

Pérez, E., 2003, La crisis de la educación indigena en el área tzoltzil de Los Altos de Chiapas, Ed. Universidad Pedagógica Nacional/ Porrúa, México, D.F.

Periódico El Universal, en http://www.eluniversal.com.mx/estados/ 81907.html

Periódico El Universal, en http://www.eluniversal.com.mx/nacion/ 189183.html 
Plan de Estudios de México 2011.

Ramírez, N., 2007, Etnografía comparativa en el ámbito educativo de algunas escuelas indigenas del Estado de Chiapas, México, EMIGRA Working Papers, 121, en http://www.emigra.org.es

Red por los Derechos de la Infancia en México, Redim, en http://www. derechosinfancia.org. $\mathrm{mx} /$ index.php [fecha de consulta: 5 de mayo de 2015].

Revista Proceso, en http://www.proceso.com.mx/?p=394174

Schmelkes, S., 2013, "Educación y pueblos indígenas", vol. 4, núm. 1, enero-abril, en http://www.inegi.org.mx/rde/RDE_08/RDE _08_Art1.html

Secretaría de Educación, 1999, La educación bilingüe-bicultural en los Altos de Chiapas. Una evaluación, Centro de Estudios Superiores de México y Centroamérica, México.

Silas, J.C., 2012, "Las universidades interculturales como un mecanismo para elevar el acceso a la educación superior de la población marginada (y de conocimiento) en México", en http://www.nexos.com.mx, México.

Ventura, L., 2012, "El derecho a la autodeterminación de los pueblos indígenas: marco para construir las estrategias de cooperación”, en García, C., P. Gil y P. Sanchiz, 2012, Las políticas de desarrollo y cooperación de las ONG en América Latina, Universidad de Sevilla, Sevilla. 